Research Article

\title{
ECC Design Based on Uniform Design Test Method and Alternating Conditional Expectation
}

\author{
Xiaoqin Li $\mathbb{D},{ }^{1}$ Xiao Yang, ${ }^{1}$ Zude Ding $\mathbb{D},{ }^{1}$ Xi Du, ${ }^{2}$ and Jincheng Wen ${ }^{1}$ \\ ${ }^{1}$ Faculty of Civil Engineering and Mechanics, Kunming University of Science and Technology, 650550 Kunming, China \\ ${ }^{2}$ Country Garden Real Estate Limited Company of Yunnan Province, 650000 Kunming, China \\ Correspondence should be addressed to Zude Ding; dzdvsdt@163.com
}

Received 2 July 2019; Revised 23 August 2019; Accepted 3 September 2019; Published 1 October 2019

Academic Editor: Alessandro Formisano

Copyright (c) 2019 Xiaoqin Li et al. This is an open access article distributed under the Creative Commons Attribution License, which permits unrestricted use, distribution, and reproduction in any medium, provided the original work is properly cited.

Engineered cementitious composites (ECC) have higher ultimate tensile strains than normal concrete. The mechanical properties of ECC strongly depend on raw materials and the mix proportions. The uniform design test method and alternating conditional expectation, which is a nonparametric regression analysis method, were used to design the ECC mix proportion. According to the regression analysis, the optimized $\mathrm{W} / \mathrm{B}, \mathrm{S} / \mathrm{B}$, and F/B ranges could be obtained as $0.35-0.42,0.25-0.3$, and 0.02 , respectively. The tested proportions for validation were randomly adopted within the range of $\mathrm{W} / \mathrm{B}, \mathrm{S} / \mathrm{B}$, and $\mathrm{F} / \mathrm{B}$. The uniaxial compression, tension, and four-point bending tests were conducted to verify the material behaviour of the designed ECC. Results showed that all the specimens had large ultimate tensile strains and high fracture energy capacities, and strain hardening was also observed. The fibers were found to be uniformly distributed in the specimens by using a scanning electron microscope. This paper may provide theoretical and practical guidance for the ECC and other cement-based material mix proportion design.

\section{Introduction}

Concrete is widely used in civil engineering. However, concrete is brittle, and its toughness decreases with its increasing strength, which may lead to cracking in structures [1-3]. Engineered cementitious composites (ECC) were developed due to the advantages in toughness and energy absorption capacities. The ultimate tensile strain of ECC is $1-8 \%$, whereas that of normal concrete is only about $0.01 \%$. Moreover, the tensile ductility of ECC is nearly 300 times that of normal concrete [4]. Polyvinyl alcohol (PVA) fiber, which is normally used in ECC [5], is an acid/alkali-resistant material with high elastic modulus, high tensile strength, and low industrial cost. In the current paper, ECC is referred to as PVA-ECC only, and the fiber volume ratio of ECC is $2 \%$ or less [6].

The mechanical properties of cement-based materials depend on their raw materials. Based on the chosen local materials, the ECC material properties are mainly controlled by mix proportions. The mix proportion design methods, which have already been used in the ECC design, include mixing proportion table method [7], absolute volume method [8], idealized comprehensive test design method, and orthogonal experimental design method [9]. For the mixing proportion table method [7], existing mix proportions of ECC from literatures and their performances, such as the specimen tensile strains, need to be carefully reviewed and listed firstly. Then, one or several mix proportions with better specimen performances can be selected accordingly, and validation tests must be conducted based on the chosen mix proportions. However, the mixing proportion table method is not scientific and rigorous enough as the raw materials are different from the literatures. The absolute volume method [8] is based on the normal concrete mixture design standard [10]. The per cubic meter of concrete mixture is equal to the sum of the absolute volume of each material and the small volume of air. According to the code JGJ 55-2011 [10], the process of absolute volume method is as follows: (1) calculate the waterbinder ratio based on the strength of concrete; (2) according to the water-binder ratio and the kinds of mineral admixture (fly ash, silica fume, etc) added, the dosage of mineral 
admixture can be obtained according to the Table 3.0.5-1 listed in the code; (3) according to the expected slump and the aggregate size, the unit water dosage can be obtained according to Table 5.2.1-2; (4) the dosage of sand based on the sand ratio can be calculated according to Equation 5.5.2 in the code; (5) $1 \%$ volume air need to be considered without air-entraining agent; (6) the initial mix proportions can be achieved, and the final mix proportions need to be done after testing and adjusting. Normal concrete mix proportions can be properly designed with this method, but large errors may exist when using this method to design ECC mix proportions due to the differences of the raw materials between normal concrete and ECC. With the idealized comprehensive test design method, a number of tests need to be conducted with different level combinations of every test factors. However, this method for mix proportion design is difficult to be achieved when the numbers of the test factors and levels are over 3 . The orthogonal experimental design method [9] is much more widely used in statistical tests and design because of its effective performance in terms of dealing with multifactor experiments and screened optimum levels $[11,12]$. However, researchers should have a clear view of the relationships between the objective function and the related factors when performing the test data regression analysis. This relationship must be implicit before the regression analysis [13].

The four design methods listed above all have disadvantages for the ECC design. In the current paper, the uniform design test method and the alternating conditional expectations were used for the ECC design based on the local materials in Kunming, Yunnan province, China. The uniform design test method performs more effectively. For instance, if $s$ is the number of the chosen design factors and $q$ is the number of factor levels, the number of tests required is $q^{s}$ when the idealized comprehensive test design method is used for the ECC design. The number of tests needed is $q^{2}$, if the orthogonal experimental design method is used, whereas the number of tests required is only $q$ when the uniform design method is chosen. Meanwhile, the alternating conditional expectation analysis used in this paper does not require a predefined explicit relationship between the objective function and the related factors. The analysis only depends on the results of the uniform design tests.

\section{Uniform Design Test Method and Alternating Conditional Expectation}

The uniform design test method was designed by Fang and Wang [14]. This test design method is based on the uniformity of the test points and is an application of the Monte Carlo method. The uniform tables and application tables [15] are used to design and organize the test data. The uniform table is a normalized table, and each table is a matrix with $n$ rows and $m$ columns. The expression of the uniform table is $U_{n}\left(q^{m}\right)$, where $U$ is the uniform table; $n$ is the number of tests required, which is normally 3-5 times that of the number for the chosen design factors; and $q$ is the number of levels of the factors. Normally, $q$ is equal to $n$, and $m$ is the number of design factors. According to the number of the chosen design factors $(s, s \leq m)$, the corresponding application tables [15] are used to determine the chosen uniform table $U_{n}\left(n^{s}\right)$. Deviations are generally used to measure the uniformity of the points in the test domain in selecting the best level combination of uniformity [14]. The most widely used deviation uniformity justification is the centered $\mathrm{L}_{2}$ discrepancy $\left(\mathrm{CD}_{2}\right)$ [14]. Equation (1) is used to map the $n \times s$ elements $u_{i j}$ in the chosen uniform table $U_{n}\left(n^{s}\right)$ to $(0,1)$, thus forming the relevant mapping table.

$$
x_{i j}=\frac{2 u_{i j}-1}{2 n},
$$

where $i=1,2, \ldots, s$ and $j=1,2, \ldots, n$. The deviation $\mathrm{CD}_{2}$ of the chosen uniform table $U_{n}\left(n^{s}\right)$ is given as follows:

$$
\mathrm{CD}_{2}(P)=\left[\left(\frac{13}{12}\right)^{s}-\frac{2^{1-s}}{n} \sum_{k=1}^{n} \prod_{i=1}^{s}\left(2+\left|x_{k i}-\frac{1}{2}\right|-\left|x_{k i}-\frac{1}{2}\right|^{2}\right)+\frac{1}{n^{2}} \sum_{k=1}^{n} \sum_{l=1}^{n} \prod_{i=1}^{s}\left(1+\frac{1}{2}\left|x_{k i}-\frac{1}{2}\right|+\frac{1}{2}\left|x_{l i}-\frac{1}{2}\right|-\frac{1}{2}\left|x_{k i}-x_{l i}\right|\right)\right]^{1 / 2} .
$$

For the uniform tests with the $s$ factors, the first step in the design process is to determine the variation range of each factor in the test, which is referred as $\left[X_{i \text { min }}, X_{i \max }\right](i=1,2$, $\ldots, s)$, where $X_{i \min }$ and $X_{i \max }$ are the minimum and maximum values of the $i$ th factor, respectively. The test design table can be obtained using the following equation:

$$
X_{i j}=X_{i \min }+\frac{j-1}{n-1}\left(X_{i \max }-X_{i \min }\right),
$$

where $i=1,2, \ldots, s$, which are the factor sequence numbers; $j=1,2, \ldots, n$ are the level sequence numbers; and $X_{i j}$ is the $j$ th level value of the $i$ th factor. The uniform table and the column number in the application table are selected according to the number of factors and levels to generate the combinative table $X\left(x_{i j}\right)$, which is a matrix with $n$ rows and $s$ columns. Thereafter, the test result table $Y\left(y_{i j}\right)$ can be obtained, which is a matrix with $n$ rows and 1 column according to the corresponding test results. Finally, the chosen regression analysis, such as alternating conditional expectations, is applied to find relationships between $X\left(x_{i j}\right)$ and $Y\left(y_{i j}\right)$.

Based on $X\left(x_{i j}\right)$ and $Y\left(y_{i j}\right)$, the alternating conditional expectation regression analysis [16] which is a nonparametric regression analysis can be applied. Compared with the parametric regression analysis, the derived function does not depend on the predefined function type but only depends on the test data and their sample size with the nonparametric regression analysis $[17,18]$. The function could be in various types, which provides more general conclusions rather than parametric regression analysis $[19,20]$. Nonparametric 
regression analysis should be used when the relationship between the test factors and results is not clear. The alternating conditional expectations aim to fit the data in an additive, nonlinear model in the form of equation (4):

$$
\theta(A)=\varphi_{1}\left(x_{1}\right)+\varphi_{2}\left(x_{2}\right)+\cdots+\varphi_{s}\left(x_{s}\right)+\delta,
$$

where $A$ is the dependent variable, $x_{i}$ is the regression variable, $\theta, \varphi_{1}, \ldots, \varphi_{s}$ are the smooth and nonlinear transformations of the data, and $\delta$ is a random residual. Nonlinear transformations are mostly used in alternating conditional expectations to maximize the correlation between $\theta(A)$ and $\varphi_{1}\left(x_{1}\right)+\cdots+\varphi_{s}\left(x_{s}\right)$ based on the data feature of the combinative table $X\left(x_{i j}\right)$ and test result table $Y\left(y_{i j}\right)$. Using the transformation of the best-fitting additive model can converge the regression function $A\left(x_{i j}\right)$ with the optimal solution. Meanwhile, the stability and symmetry of the random error $\varepsilon_{i}$ can be satisfied. The target function can be determined by using the following equation:

$$
A=\theta^{-1}\left[\varphi_{1}\left(x_{1}\right)+\varphi_{2}\left(x_{2}\right)+\cdots+\varphi_{s}\left(x_{s}\right)\right]+\delta_{2},
$$

where $\theta^{-1}[\cdot]$ is the inverse function of $\theta$. S-Plus [21] can provide the alternating conditional expectation regression process. Only a specific command is required to invoke the calculation to obtain the results, including the transformation data set with the maximal correlation for the combinative table $X\left(x_{i j}\right)$ and the test result table $Y\left(y_{i j}\right)$. Accordingly, the relationship between $\theta(A)$ and $\varphi_{1}\left(x_{1}\right), \varphi_{2}\left(x_{2}\right), \ldots, \varphi_{s}\left(x_{s}\right)$ can be determined via interpolation algorithm with the following equation:

$$
\varphi_{i}\left(x_{i}\right)=\operatorname{interp}\left(x_{i}, X_{i j}, X_{i}\right), \quad i=1,2, \ldots, s,
$$

where $\varphi_{i}\left(x_{i}\right)$ is a nonlinear transformation correlation between the combinative table $X\left(x_{i j}\right)$ and the test target $A ; x_{i}$ is the test vector of each factor; $X_{i j}$ is the maximum correlation transform data of the combinative table $X\left(x_{i j}\right)$; and $X_{i}$ is the test factor. $\theta(A)$ is given by the following equation:

$$
\theta(A)=\sum_{i=1}^{s} \varphi_{i}\left(X_{i}\right)
$$

The test target is given using the following equation:

$$
A=\operatorname{interp}\left(A_{\mathrm{t}}, y_{i}, \theta(A)\right),
$$

where $y_{i}$ is the test result vector of the target and $A_{\mathrm{t}}$ is the transformed data of the test result $Y\left(y_{i j}\right)$. Based on the above calculations, a developed interpolation algorithm program in MATLAB can be implemented to complete the construction of the target function relationship.

\section{ECC Design Based on the Uniform Design Test Method and the Alternating Conditional Expectation}

3.1. Raw Materials. Local materials from Kunming, Yunnan province, China were used as the raw materials for the ECC design, including the P.O 42.5 cement, class F fly ash, and quartz sand. The material properties of the cement and fly ash are listed in Tables 1 and 2 . The quartz sand with a grain
TABLE 1: Material properties of cement.

\begin{tabular}{lcc}
\hline Curing time & $\begin{array}{c}\text { Compressive strength } \\
(\mathrm{MPa})\end{array}$ & $\begin{array}{c}\text { Bending strength } \\
(\mathrm{MPa})\end{array}$ \\
\hline $7 \mathrm{~d}$ & 18.9 & 4.2 \\
$28 \mathrm{~d}$ & 45.3 & 7.6 \\
\hline
\end{tabular}

TABLe 2: Material properties of fly ash.

\begin{tabular}{lcccc}
\hline $\begin{array}{l}45 \mu \mathrm{m} \text { Sieve } \\
\text { residue (\%) }\end{array}$ & $\begin{array}{c}\text { Water demand } \\
\text { ratio }\end{array}$ & $\begin{array}{c}\mathrm{LOI} \\
(\%)\end{array}$ & $\begin{array}{c}\mathrm{SO}_{3} \\
(\%)\end{array}$ & $\begin{array}{c}\text { Water content } \\
(\%)\end{array}$ \\
\hline 11.2 & 90 & 4.5 & 2.5 & 0.8 \\
\hline
\end{tabular}

size between $0.2 \mathrm{~mm}$ and $0.4 \mathrm{~mm}$ was used as fine aggregates. The PVA fiber produced in Japan was used, and its material properties are listed in Table 3. The water-reducing admixture is polycarboxylate superplasticizer, and its waterreducing rate is $20 \%$. The water-reducing admixture is not set as the design factor. Therefore, the dosage of the waterreducing admixture is based on the sump test of ECC, which is case dependent. The final water-reducing admixture to cement mass ratios are between $0--0.022$.

3.2. ECC Mix Proportion Uniform Test Design. The target of the ECC mix proportion design is to obtain the ECC mixture with a high ultimate tensile strain and large fracture energy at a certain strength. Based on former engineering experience $[7,13,22-35]$, the water-to-binder ratio mainly affects the strength of the cement matrix; the fiber mainly affects the ultimate tensile strain capacity and the fracture energy of ECC; the quartz sand which was used as filler mainly affects the mixing process because sand could improve the fluidity of cement-based materials including ECC; and the waterreducing admixture mainly affects the compactness, fluidity, and workability of the cement matrix. Accordingly, fiber/ cement mass ratio and water-to-binder ratios were determined as the main factors for the ECC design. The waterto-binder ratio involves two variables, including the fly ash/ cement mass ratio and the water/cement mass ratio. Therefore, cement was used as the benchmark component for the tests. Fly ash/cement mass ratio, water-cement mass ratio, and fiber/cement mass ratio were finally determined as the three main factors, while the quartz sand and waterreducing admixture were chosen as two minor factors. The ranges of the main factors were determined according to statistics based on existing work on ECC [7, 13, 22-35]. According to the existing data base $[7,13,22-35]$, the range of the fly ash/cement mass ratio is from 0.11 to 3.00 , the water-cement ratio is from 0.42 to 1.2 , and the fiber/mortar volume ratio $V_{\mathrm{f}}$ is $0-2 \%$. Using the fiber/cement mass ratio $R_{\mathrm{fc}}$ is more convenient than the volume ratio for data analysis. Therefore, the fiber mass $\mathrm{M}_{\mathrm{f}}$ was used to replace the fiber/mortar volume ratio $V_{\mathrm{f}}$ according to the following equation:

$$
M_{\mathrm{f}}=\frac{M_{\mathrm{m}}}{D_{\mathrm{m}}} \times V_{\mathrm{f}} \times D_{\mathrm{f}},
$$

where $M_{\mathrm{m}}$ is the mass of the mortar $(\mathrm{kg}) ; D_{\mathrm{m}}$ is the density of the mortar, which is supposed to be $1900 \mathrm{~kg} / \mathrm{m}^{3}$ [36]; and $D_{\mathrm{f}}$ 
TABLE 3: Material properties of PVA fiber.

\begin{tabular}{lccccc}
\hline Diameter $(\mu \mathrm{m})$ & Length $(\mathrm{mm})$ & Density $\left(\mathrm{g} \cdot \mathrm{cm}^{-3}\right)$ & Tensile strength $(\mathrm{MPa})$ & Elastic modulus $(\mathrm{GPa})$ & Elongation $(\%)$ \\
\hline 39 & 12 & 1.3 & 1620 & 42.8 & 7 \\
\hline
\end{tabular}

is the density of the fiber, which is $1.3 \mathrm{~g} / \mathrm{cm}^{3}$. The fiber/cement mass ratio $R_{\mathrm{fc}}$ was obtained with the following equation:

$$
R_{\mathrm{fc}}=\frac{M_{\mathrm{f}}}{M_{\mathrm{c}}}
$$

where $M_{\mathrm{c}}$ is the mass of the cement. The two minor factors are adjusted during the test based on specific test conditions.

Considering both empirical cost and accuracy, each main factor was divided into 10 levels. $U_{10}^{*}\left(10^{8}\right)(D=0.1681)$ uniform table (Table 4) and the application table (Table 5) (Fang [15]) were selected based on the number of tests, levels, and small deviance. Because the number of factors is three, according to the application Table 5, columns 1, 5, and 6 of the uniform Table 4, representing fly ash/cement mass ratio, water-cement ratio, and fiber/cement mass ratio, were used in the test design. The data in Table 4 were mapped to $(0,1)$ by using equation $(1)$, and the results are listed in Table 6 .

Based on equation (2), the uniformity of the mapping table can be evaluated. The value of deviation $\mathrm{CD}_{2}$ was 0.096 for the chosen tables, which was smaller than the deviance of $U_{10}^{*}\left(10^{8}\right)$, which was 0.1681 . This indicated that the chosen uniform table had good uniformity. The uniform-designed ECC mix proportions could be obtained using equation (3) and listed in Table 7, and the tests were performed accordingly. Results were briefly presented in the remark column.

Six mix proportions listed in Table 7 could not be mixed and stirred properly. Therefore, the fifth column data in the uniform table (Table 4), which correspond to the watercement ratio (w/c) in the fourth column in Table 7 , were designed to be replaced according to the workability of the mixtures. By supposing $A_{i, 5}$ stands for the data of row $i$ and column 5 in the uniform table $U_{10}^{*}\left(10^{8}\right)$, the proper replacement operation was $A_{1,5} \longrightarrow A_{9,5}, \quad A_{2,5} \longrightarrow A_{7,5}$, $A_{7,5} \longrightarrow A_{1,5}, A_{9,5} \longrightarrow A_{10,5}$, and $A_{10,5} \longrightarrow A_{2,5}$. The adjusted uniform table is presented in Table 8 . The data are mapped in Table 8 to $(0,1)$ by using equation $(1)$, and the results are listed in Table 9.

Based on equation (2), the uniformity of the adjusted mapping table (Table 9) was re-evaluated, and the value of the deviation $\mathrm{CD}_{2}$ is $0.1141(0.1141<0.1681)$, which means that the adjusted uniform table still had good uniformity. Equation (3) was used again to obtain the adjusted uniform designed ECC mix proportions, which is listed in Table 10. The test results indicated that all the mix proportions can be successfully processed. In Table $10, \mathrm{~W} / \mathrm{B}$ is the water/binder mass ratio, $\mathrm{S} / \mathrm{B}$ is the sand/binder mass ratio, $\mathrm{F} / \mathrm{B}$ is the fiber/ binder mass ratio, and $\mathrm{H} / \mathrm{B}$ is the ratio of the water-reducing admixture to the cementitious materials.

The ECC mixing process is as follows: (1) the cement, fly ash, quartz sand, fibers, water, and water-reducing admixture were weighed and prepared separately; (2) the cement,
TABLe 4: Uniform table $U_{10}^{*}\left(10^{8}\right)$.

\begin{tabular}{ccccccccc}
\hline & 1 & 2 & 3 & 4 & 5 & 6 & 7 & 8 \\
\hline 1 & 1 & 2 & 3 & 4 & 5 & 7 & 9 & 10 \\
2 & 2 & 4 & 6 & 8 & 10 & 3 & 7 & 9 \\
3 & 3 & 6 & 9 & 1 & 4 & 10 & 5 & 8 \\
4 & 4 & 8 & 1 & 5 & 9 & 6 & 3 & 7 \\
5 & 5 & 10 & 4 & 9 & 3 & 2 & 1 & 6 \\
6 & 6 & 1 & 7 & 2 & 8 & 9 & 10 & 5 \\
7 & 7 & 3 & 10 & 6 & 2 & 5 & 8 & 4 \\
8 & 8 & 5 & 2 & 10 & 7 & 1 & 6 & 3 \\
9 & 9 & 7 & 5 & 3 & 1 & 8 & 4 & 2 \\
10 & 10 & 9 & 8 & 7 & 6 & 4 & 2 & 1 \\
\hline
\end{tabular}

TABLE 5: Application form for $U_{10}^{*}\left(10^{8}\right)$.

\begin{tabular}{lcc}
\hline The number of factors & Column number & $D$ \\
\hline 2 & 16 & 0.1125 \\
3 & 156 & 0.1681 \\
4 & 1345 & 0.2236 \\
5 & 13457 & 0.2414 \\
6 & 12356 & 0.2994 \\
\hline
\end{tabular}

TABLE 6: Mapping table.

\begin{tabular}{ccccccccc}
\hline & 1 & 2 & 3 & 4 & 5 & 6 & 7 & 8 \\
\hline 1 & 0.05 & 0.15 & 0.25 & 0.35 & 0.45 & 0.65 & 0.85 & 0.95 \\
2 & 0.15 & 0.35 & 0.55 & 0.75 & 0.95 & 0.25 & 0.65 & 0.85 \\
3 & 0.25 & 0.55 & 0.85 & 0.05 & 0.35 & 0.95 & 0.45 & 0.75 \\
4 & 0.35 & 0.75 & 0.05 & 0.45 & 0.85 & 0.55 & 0.25 & 0.65 \\
5 & 0.45 & 0.95 & 0.35 & 0.85 & 0.25 & 0.15 & 0.05 & 0.55 \\
6 & 0.55 & 0.05 & 0.65 & 0.15 & 0.75 & 0.85 & 0.95 & 0.45 \\
7 & 0.65 & 0.25 & 0.95 & 0.55 & 0.15 & 0.45 & 0.75 & 0.35 \\
8 & 0.75 & 0.45 & 0.15 & 0.95 & 0.65 & 0.05 & 0.55 & 0.25 \\
9 & 0.85 & 0.65 & 0.45 & 0.25 & 0.05 & 0.75 & 0.35 & 0.15 \\
10 & 0.95 & 0.85 & 0.75 & 0.65 & 0.55 & 0.35 & 0.15 & 0.05 \\
\hline
\end{tabular}

fly ash, and quartz sand were mixed as the dry mix and stirred for 5-8 minutes in cement mortar mixer; (3) the water-reducing admixture was added into the water and stirred for 3-5 minutes; (4) the liquid was poured into the dry mix, and the wet mix was stirred for about 10 minutes to ensure that the cement matrix was mixed uniformly; (5) the fibers were uniformly sprinkled into the wet cement matrix as the stirring mill working at a low speed (about $140 \mathrm{rpm}$ ); (6) the final mixing process was kept at a low speed for 2-3 minutes at first, and then at a high speed (about $285 \mathrm{rpm}$ ) for 4-6 minutes, and finally at low speed stirring for 2-3 minutes to ensure that the fibers were uniformly distributed in the cement matrix without agglomeration; (7) the stirred ECC mixture was poured into the mold and smoothed with a spatula. The specimen was vibrated on the shaking table for 1 minute to keep the compactness. The surface of the specimen was smeared with a spatula, and the specimens were stored 
TABLE 7: ECC mix proportion uniform design table (mass ratios).

\begin{tabular}{lccccccc}
\hline No. & Cement & Fly ash & w/c & Fiber & Quartz sand & Water-reducing admixture & Remarks \\
\hline 1 & 1.0 & 0.110 & 0.767 & 0.022 & 1.0 & 0.012 & Failure, too much water, unworkable \\
2 & 1.0 & 0.431 & 1.200 & 0.008 & 1.4 & 0.001 & Failure, too much water, unworkable \\
3 & 1.0 & 0.752 & 0.680 & 0.04 & 0.6 & 0.013 & Success \\
4 & 1.0 & 1.073 & 1.113 & 0.036 & 1.6 & 0.001 & Success \\
5 & 1.0 & 1.394 & 0.593 & 0.005 & 0.6 & 0.015 & Success \\
6 & 1.0 & 1.716 & 1.027 & 0.055 & 0.7 & 0.001 & Success \\
7 & 1.0 & 2.037 & 0.507 & 0.029 & 0.3 & 0.036 & Failure, insufficient water, unworkable \\
8 & 1.0 & 2.358 & 0.940 & 0.00 & 1.0 & 0.016 & Success \\
9 & 1.0 & 2.679 & 0.420 & 0.059 & 0.2 & 0.04 & Failure, insufficient water, unworkable \\
10 & 1.0 & 3.000 & 0.853 & 0.031 & 0.4 & 0.04 & Failure, insufficient water, unworkable \\
\hline
\end{tabular}

TABLE 8: Adjusted uniform table $U_{10}^{*}\left(10^{8}\right)$.

\begin{tabular}{ccccccccc}
\hline & 1 & 2 & 3 & 4 & 5 & 6 & 7 & 8 \\
\hline 1 & 1 & 7 & 3 & 4 & 1 & 7 & 9 & 10 \\
2 & 2 & 3 & 6 & 8 & 2 & 3 & 7 & 9 \\
3 & 3 & 6 & 9 & 1 & 4 & 10 & 5 & 8 \\
4 & 4 & 8 & 1 & 5 & 9 & 6 & 3 & 7 \\
5 & 5 & 10 & 4 & 9 & 3 & 2 & 1 & 6 \\
6 & 6 & 1 & 7 & 2 & 8 & 9 & 10 & 5 \\
7 & 7 & 2 & 10 & 6 & 5 & 5 & 8 & 4 \\
8 & 8 & 5 & 2 & 10 & 7 & 1 & 6 & 3 \\
9 & 9 & 4 & 5 & 3 & 6 & 8 & 4 & 2 \\
10 & 10 & 9 & 8 & 7 & 10 & 4 & 2 & 1 \\
\hline
\end{tabular}

TABle 9: Adjusted mapping table.

\begin{tabular}{lcccccccc}
\hline & 1 & 2 & 3 & 4 & 5 & 6 & 7 & 8 \\
\hline 1 & 0.05 & 0.15 & 0.25 & 0.35 & 0.05 & 0.65 & 0.85 & 0.95 \\
2 & 0.15 & 0.35 & 0.55 & 0.75 & 0.15 & 0.25 & 0.65 & 0.85 \\
3 & 0.25 & 0.55 & 0.85 & 0.05 & 0.35 & 0.95 & 0.45 & 0.75 \\
4 & 0.35 & 0.75 & 0.05 & 0.45 & 0.85 & 0.55 & 0.25 & 0.65 \\
5 & 0.45 & 0.95 & 0.35 & 0.85 & 0.25 & 0.15 & 0.05 & 0.55 \\
6 & 0.55 & 0.05 & 0.65 & 0.15 & 0.75 & 0.85 & 0.95 & 0.45 \\
7 & 0.65 & 0.25 & 0.95 & 0.55 & 0.45 & 0.45 & 0.75 & 0.35 \\
8 & 0.75 & 0.45 & 0.15 & 0.95 & 0.65 & 0.05 & 0.55 & 0.25 \\
9 & 0.85 & 0.65 & 0.45 & 0.25 & 0.55 & 0.75 & 0.35 & 0.15 \\
10 & 0.95 & 0.85 & 0.75 & 0.65 & 0.95 & 0.35 & 0.15 & 0.05 \\
\hline
\end{tabular}

in the laboratory at normal temperature (about $20^{\circ} \mathrm{C}$ ) and humidity (about 65\% rh) for 24 hours. After mold stripping, the specimens were stored in the standard curing room for 28 days.

\subsection{Uniform Design Specimen Tests}

3.3.1. Uniaxial Compression Tests. In uniaxial compression tests, the dimension of the specimens is $100 \mathrm{~mm} \times 100 \mathrm{~mm} \times$ $100 \mathrm{~mm}$. The tests were carried out in a $1000 \mathrm{kN}$ capacity hydraulic servo universal testing machine using linear variable differential transformers (LVDTs) to measure the uniaxial deformation on both sides, as shown in Figure 1. Displacement control mode was adopted as the loading method during the tests, and the loading rate was controlled at $1.5 \mathrm{~mm} / \mathrm{min}$. The reaction force at the top of the specimen was read by the machine. Results showed that the ECC specimens maintained their integrity and exhibited a ductile failure under compression (Figure 2). Figure 3 presents the compressive engineering stress-strain curves for the No. 2 and No. 8 mix proportion specimens, which have a fiber/ cement mass ratio of 0.0551 and 0 , respectively. Adding PVA fibers can enhance compressive strength and the compressive fracture energy of ECC by controlling cracks.

3.3.2. Uniaxial Tension Tests. Dumbbell-shaped specimens were prepared as shown in Figure 4 to test the tensile stressstrain behavior of the ECC.

The tensile specimens were tested under displacement control at a loading rate of $0.15 \mathrm{~mm} / \mathrm{min}$ on a $10 \mathrm{kN}$ capacity electro-mechanical universal testing machine with two ends pin-ended as shown in Figures 4 and 5. An extensometer with $5 \mathrm{~mm}$ measurement range and $0.025 \mathrm{~mm}$ resolution was used to detect the tensile deformation of the tested section. The both ends of the extensometer were fixed exactly at the upper and lower boundary of the tested section shown in Figures 4 and 5. The tensile force was measured by the load cell. The tested engineering stress-strain curves of No. 6 and No. 8 specimens are presented in Figure 6, which indicates that adding PVA fibers effectively increased the ultimate tensile strain and the toughness of the specimens. The high tensile ductility and multiple cracking of ECC are due to the synergy effect of the matrix, fibers, and fibermatrix interface under tension $[37,38]$. The PVA fibers were randomly distributed in the matrix. Before cracking, the fibers could inhibit the production of cracks and improve the compactness of the matrix. After cracking, the matrix transferred stress to the fibers at the crack, and then fibers transferred stress to the uncracked matrix leading stress redistributions, which might involve multiple cracking and improve the ductility of ECC.

3.3.3. Uniform Design Test Results. The uniaxial tensile strength $f_{\mathrm{t}}(\mathrm{MPa})$, ultimate tensile strain $\varepsilon_{\mathrm{cu}}$, fracture energy $G_{\mathrm{F}}^{\mathrm{I}}(\mathrm{N} / \mathrm{m})$, and uniaxial compressive strength $f_{\mathrm{c}}(\mathrm{MPa})$ of the mix proportions listed in Table 10 were tested and presented in Table 11. PVA fibers showed a great improvement for ultimate tensile strain $\varepsilon_{\mathrm{cu}}$, and fracture energy $G_{\mathrm{F}}^{\mathrm{I}}$ compared with the cement matrix without fibers.

3.4. Alternating Conditional Expectation Analysis. The alternating conditional expectation analysis was used for the 
TABle 10: Adjusted uniform design table for ECC mix proportion design (mass ratio).

\begin{tabular}{lcccccccccc}
\hline No. & Cement & Fly ash & w/c & Fiber & Quartz sand & Water-reducing admixture & W/B & S/B & F/B & H/B \\
\hline 1 & 1.0 & 0.11 & 0.42 & 0.0224 & 1 & 0.012 & 0.378 & 0.901 & 0.020 & 0.0108 \\
2 & 1.0 & 0.43 & 0.51 & 0.0075 & 0.8 & 0.009 & 0.357 & 0.559 & 0.0052 & 0.0063 \\
3 & 1.0 & 0.75 & 0.68 & 0.041 & 0.6 & 0.001 & 0.389 & 0.343 & 0.0234 & 0.0006 \\
4 & 1.0 & 1.07 & 1.11 & 0.0358 & 1.6 & 0.001 & 0.536 & 0.773 & 0.0173 & 0.0005 \\
5 & 1.0 & 1.39 & 0.59 & 0.0049 & 0.6 & 0.015 & 0.247 & 0.251 & 0.0021 & 0.0063 \\
6 & 1.0 & 1.72 & 1.03 & 0.0551 & 0.7 & 0.001 & 0.379 & 0.257 & 0.0203 & 0.0004 \\
7 & 1.0 & 2.04 & 0.77 & 0.0289 & 0.9 & 0.014 & 0.253 & 0.296 & 0.0095 & 0.0046 \\
8 & 1.0 & 2.36 & 0.94 & 0.0000 & 1 & 0.016 & 0.279 & 0.298 & 0 & 0.0048 \\
9 & 1.0 & 2.68 & 0.85 & 0.0586 & 0.8 & 0.04 & 0.231 & 0.217 & 0.0159 & 0.0109 \\
10 & 1.0 & 3.00 & 1.20 & 0.0305 & 1.2 & 0.014 & 0.300 & 0.300 & 0.0076 & 0.0035 \\
\hline
\end{tabular}

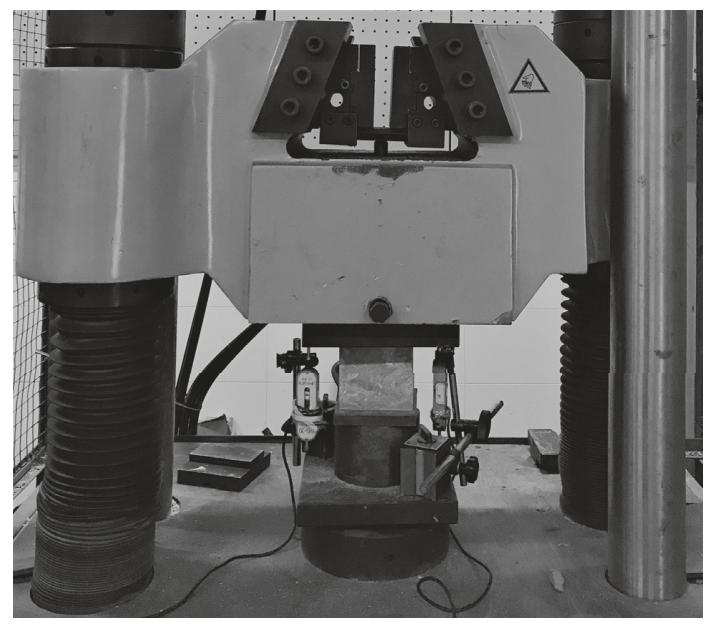

Figure 1: ECC uniaxial compression test.

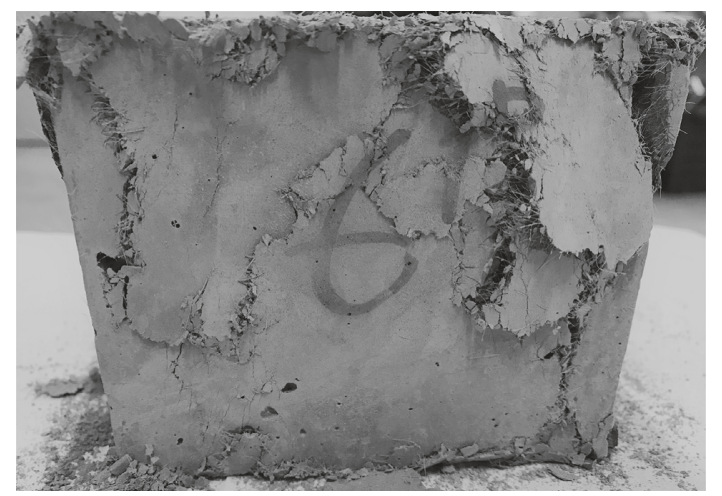

Figure 2: Failure mode of the ECC uniaxial compression test specimen.

regression analysis based on the test data and results listed in Table 11 to obtain the optimized ECC mix proportion with large ultimate tensile strain $\varepsilon_{\mathrm{cu}}$ and fracture energy $G_{\mathrm{F}}^{\mathrm{I}}(\mathrm{N} /$ $\mathrm{m})$. The regression parameters were $\mathrm{W} / \mathrm{B}, \mathrm{F} / \mathrm{B}$, and $\mathrm{S} / \mathrm{B}$, which were determined due to the interaction between the test factors. With the alternating conditional expectation analysis, the derived alternating conditional expectation analysis fitting coefficients of $\varepsilon_{\text {cu-max }}$ and $G_{\text {Fmax }}^{\mathrm{I}}$ were 0.92 and 0.98 , respectively, which were close to 1.0 . These values reflect that the fitting coefficients of the two optimal targets $\varepsilon_{\text {cu-max }}$ and $G_{\text {Fmax }}^{\mathrm{I}}$ were high enough. However, the fitting

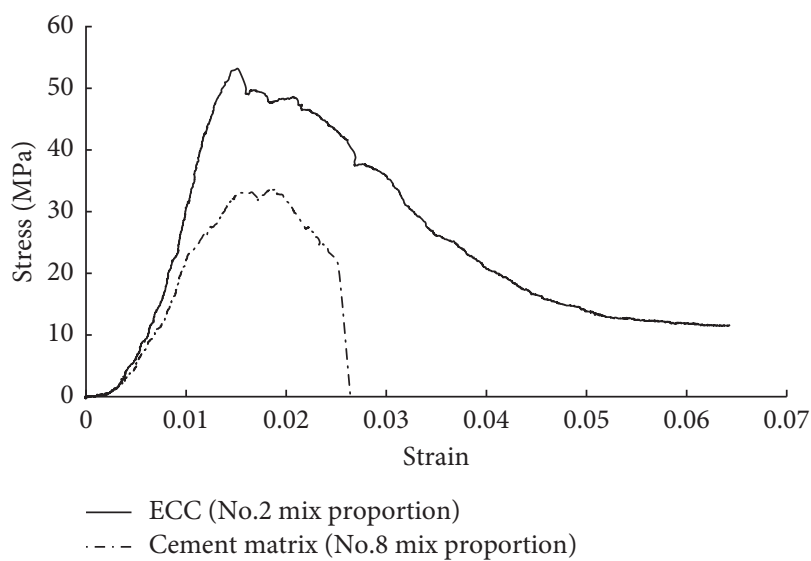

FIgURE 3: ECC and cement compressive stress-strain curves.

coefficient of $f_{\mathrm{c}}$ was only 0.62 , which means that $f_{\mathrm{c}}$ cannot be set as an optimal target based on the designed uniform test data. In Table 12, the selected regression parameters $x_{1}, x_{2}$, and $x_{3}$ stand for $\mathrm{W} / \mathrm{B}, \mathrm{F} / \mathrm{B}$, and $\mathrm{S} / \mathrm{B}$, respectively. The regression targets $y_{1}$ and $y_{2}$ stand for the optimal targets $\varepsilon_{\mathrm{cu}}$ and $G_{\mathrm{F}}^{\mathrm{I}}$, separately.

The alternating conditional expectation command in the S-PLUS was used to obtain the mapping relationships between the regression parameters $\left(x_{1}, x_{2}, x_{3}\right)$ and the maximal correlation data $\left(X_{1 \mathrm{t}}, X_{2 \mathrm{t}}, X_{3 \mathrm{t}}\right)$ for regression targets $y_{1}$ and $y_{2}$. The transformation correlation between $x_{1}$ and $X_{1 \mathrm{t}}, x_{2}$ and $X_{2 \mathrm{t}}$, and $x_{3}$ and $X_{3 \mathrm{t}}$ represented the transformation correlations of $\varepsilon_{\mathrm{cu}}, G_{\mathrm{F}}^{\mathrm{I}}$, and the regression parameters. The results were summarized into figures as shown in Figure 7. The analysis results indicated that increasing $\mathrm{W} / \mathrm{B}$ and $\mathrm{F} / \mathrm{B}$ could increase the ECC ultimate tensile strain $\varepsilon_{\mathrm{cu}}$. Decreasing $\mathrm{S} / \mathrm{B}$ would increase the ECC ultimate tensile strain $\varepsilon_{\mathrm{cu}}$. The fracture energy $G_{\mathrm{F}}^{\mathrm{I}}$ of ECC could increase as the W/B increased, but when the W/B was over $0.45, G_{\mathrm{F}}^{\mathrm{I}}$ showed a downward trend as $\mathrm{W} / \mathrm{B}$ increased. The fracture energy $G_{\mathrm{F}}^{\mathrm{I}}$ of ECC can be increased by decreasing S/B or increasing F/B. The porosity of the ECC matrix could be increased as the water-binder ratio $\mathrm{W} / \mathrm{B}$ increasing, inducing the reduction of the cementation between fiber and matrix. This may cause ECC strength reduction when the water-binder ratio $\mathrm{W} / \mathrm{B}$ is over 0.45 . Meanwhile, the elasticity modulus of ECC may also reduce due to the increasing porosity when the waterbinder ratio $\mathrm{W} / \mathrm{B}$ is over 0.45 . Therefore, though the ultimate 


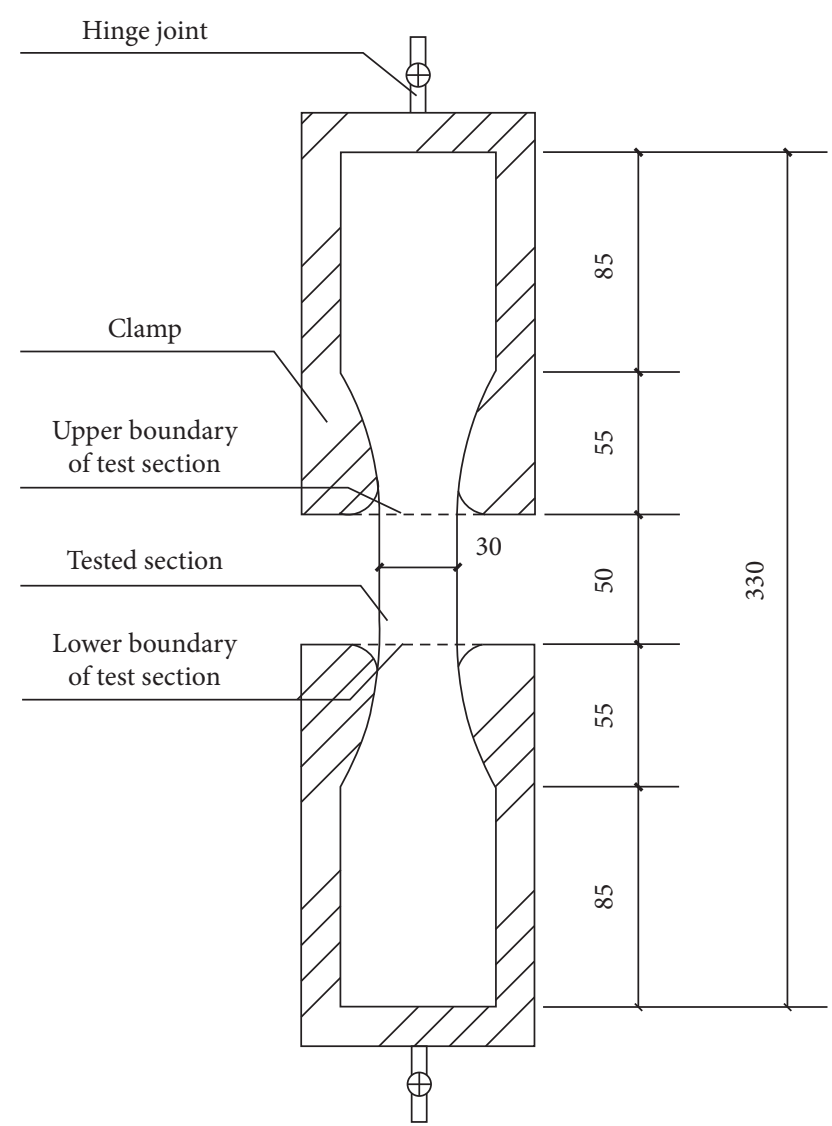

FIgURE 4: The dumbbell-shaped ECC specimen and the uniaxial tension clamp (Unit: $\mathrm{mm}$ ).

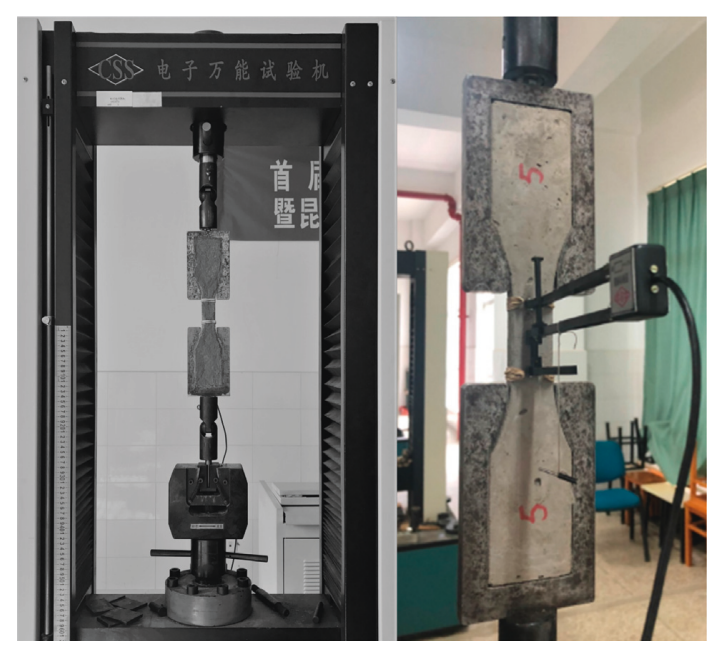

FIgURe 5: ECC uniaxial tension test.

tensile strain $\varepsilon_{\mathrm{cu}}$ in Figure 7 (a) keeps increasing, the fracture energy $G_{\mathrm{F}}^{\mathrm{I}}$ in Figure 7(b) which is related to the area under the stress-strain curve may decrease when the water-binder ratio $\mathrm{W} / \mathrm{B}$ is over 0.45 .

Based on the optimal targets $\left(\varepsilon_{\text {cu-max }}\right.$ and $\left.G_{\text {Fmax }}^{\mathrm{I}}\right)$ and the constraint conditions, the range of the regression parameters $(\mathrm{W} / \mathrm{B}, \mathrm{F} / \mathrm{B}$, and $\mathrm{S} / \mathrm{B})$ were selected via an interpolation algorithm program (MATLAB). 100,000 independent random

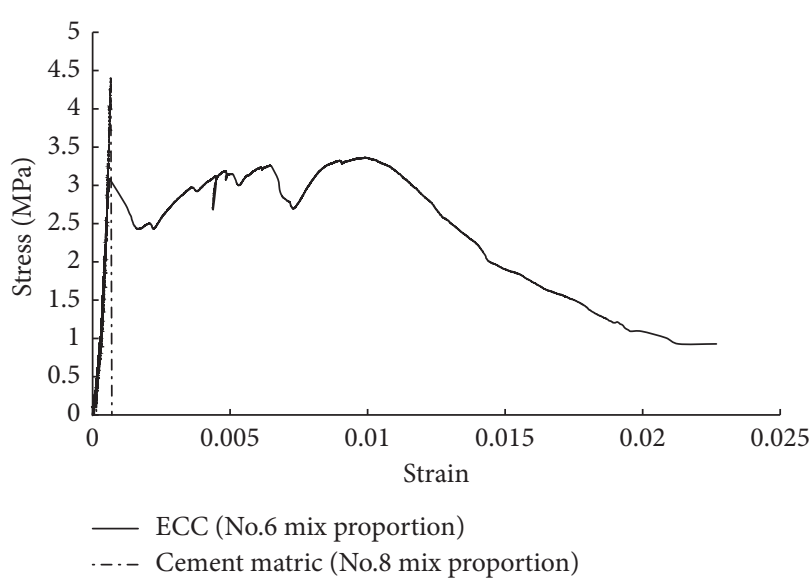

FIGURE 6: ECC and cement tensile stress-strain curves.

sampling calculations were carried out, and the maximum value of the regression target $\left(y_{1}\right.$ or $\left.y_{2}\right)$ and its corresponding series of regression parameters $\left(x_{1}, x_{2}, x_{3}\right)$ were chosen. Sampling and selection were repeated for 15 times for either of the regression target $\left(y_{1}\right.$ or $\left.y_{2}\right)$. The sampling results were summarized into trend figures as shown in Figures 8 and 9. According to the dispersion of the data points in the figures and the analysis of sampling results, the optimized mix proportion of ECC can be obtained by selecting the intersection of each regression parameter shown in Table 13.

\section{Verification Tests}

For the verification tests, MATLAB was used to randomly select five ECC mix proportions within the range of the optimized mix proportion, which are listed in Table 14. The tests were performed to verify whether the range of the mix proportion in Table 13 has a high ultimate tensile strain $\varepsilon_{\mathrm{cu}}$ and fracture energy $G_{\mathrm{F}}^{\mathrm{I}}$. Therefore, the ECC uniaxial tensile tests were chosen as the verification tests. The four-point bending tests were performed to determine the behavior of the ECC slab with the optimized mix proportion. Scanning electron microscopy (SEM) was used to detect the fiber distributions in the tested specimens.

4.1. Uniaxial Tensile Tests. The arrangement in the verification tests was the same as that of the uniaxial tensile tests as presented previously. The stress-strain curves of the dumbbell-shaped specimens with the five chosen mix proportions are presented in Figure 10. The test results are also compared in Table 15. The ECC ultimate tensile strains $\varepsilon_{\mathrm{cu}}$ for the mix proportions within the range of the optimized proportions were between $3.8 \%$ and $6.7 \%$, which were 300-500 times of that of normal concrete. The ECC fracture energies $G_{\mathrm{F}}^{\mathrm{I}}$ were between $2546.78 \mathrm{~N} / \mathrm{m}$ and $5980.43 \mathrm{~N} / \mathrm{m}$, which is $10-20$ times to that of normal concrete. Results showed that all the randomly adopted mix proportions had high ultimate tensile strains and energy absorption capacities. In addition, strain hardening and multiple cracking also occurred during the failure process as presented in 
TABLE 11: Test results for adjusted uniform designed ECC mix proportions.

\begin{tabular}{|c|c|c|c|c|c|c|c|c|c|c|}
\hline No. & Cement & Fly ash & $\mathrm{w} / \mathrm{c}$ & Fiber & Quartz sand & Water-reducing admixture & $f_{\mathrm{t}}(\mathrm{MPa})$ & $\varepsilon_{\mathrm{cu}}(\%)$ & $G_{\mathrm{F}}\left(\mathrm{N} \cdot \mathrm{m}^{-1}\right)$ & $f_{\mathrm{c}}(\mathrm{MPa})$ \\
\hline 1 & 1 & 0.11 & 0.42 & 0.0224 & 1 & 0.012 & 2.3 & 1.9 & 1087.15 & 49.67 \\
\hline 2 & 1 & 0.43 & 0.51 & 0.0075 & 0.8 & 0.009 & 4.2 & 0.6 & 648.84 & 54.33 \\
\hline 3 & 1 & 0.75 & 0.68 & 0.041 & 0.6 & 0.013 & 4.4 & 2.2 & 1936.85 & 31.33 \\
\hline 4 & 1 & 1.07 & 1.11 & 0.0358 & 1.6 & 0.001 & 2.5 & 2 & 826.84 & 23.73 \\
\hline 5 & 1 & 1.39 & 0.59 & 0.0049 & 0.6 & 0.015 & 5.5 & 0.24 & 309.21 & 68.67 \\
\hline 6 & 1 & 1.72 & 1.03 & 0.0551 & 0.7 & 0.001 & 3.4 & 2.4 & 2234.01 & 30.33 \\
\hline 7 & 1 & 2.04 & 0.77 & 0.0289 & 0.9 & 0.014 & 2.9 & 0.4 & 234.08 & 48.00 \\
\hline 8 & 1 & 2.36 & 0.94 & 0.0000 & 1 & 0.016 & 4.4 & 0.01 & 47.69 & 32.00 \\
\hline 9 & 1 & 2.68 & 0.85 & 0.0586 & 0.8 & 0.022 & 2.5 & 1.8 & 1414.03 & 48.33 \\
\hline 10 & 1 & 3.00 & 1.20 & 0.0305 & 1.2 & 0.014 & 1.4 & 1.5 & 880.46 & 33.67 \\
\hline
\end{tabular}

TABLE 12: Input parameters for regression analysis.

\begin{tabular}{|c|c|c|c|c|c|}
\hline No. & $x_{1}$ & $x_{2}$ & $x_{3}$ & $y_{1}(\%)$ & $y_{2}$ \\
\hline 1 & 0.378 & 0.020 & 0.901 & 1.9 & 1087.15 \\
\hline 2 & 0.357 & 0.0052 & 0.559 & 0.6 & 648.84 \\
\hline 3 & 0.389 & 0.0234 & 0.343 & 2.2 & 1936.85 \\
\hline 4 & 0.536 & 0.0173 & 0.773 & 2 & 920.62 \\
\hline 5 & 0.247 & 0.0021 & 0.251 & 0.24 & 309.21 \\
\hline 6 & 0.379 & 0.0203 & 0.257 & 2.4 & 2234.01 \\
\hline 7 & 0.253 & 0.0095 & 0.296 & 0.4 & 234.08 \\
\hline 8 & 0.279 & 0.0000 & 0.298 & 0.01 & 47.69 \\
\hline 9 & 0.231 & 0.0159 & 0.217 & 1.8 & 1414.03 \\
\hline 10 & 0.300 & 0.0076 & 0.300 & 1.5 & 880.46 \\
\hline
\end{tabular}
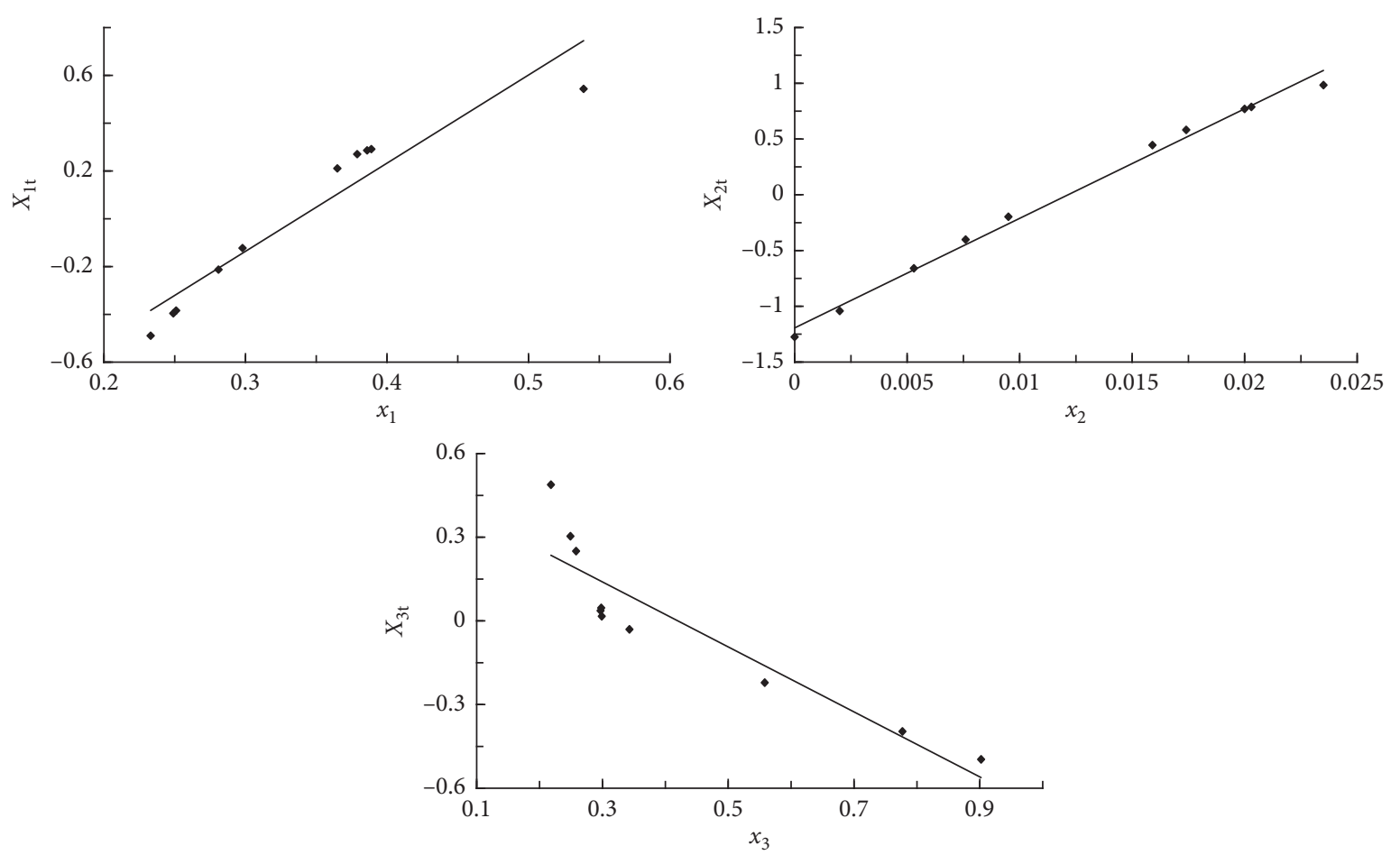

(a)

FIGURE 7: Continued. 

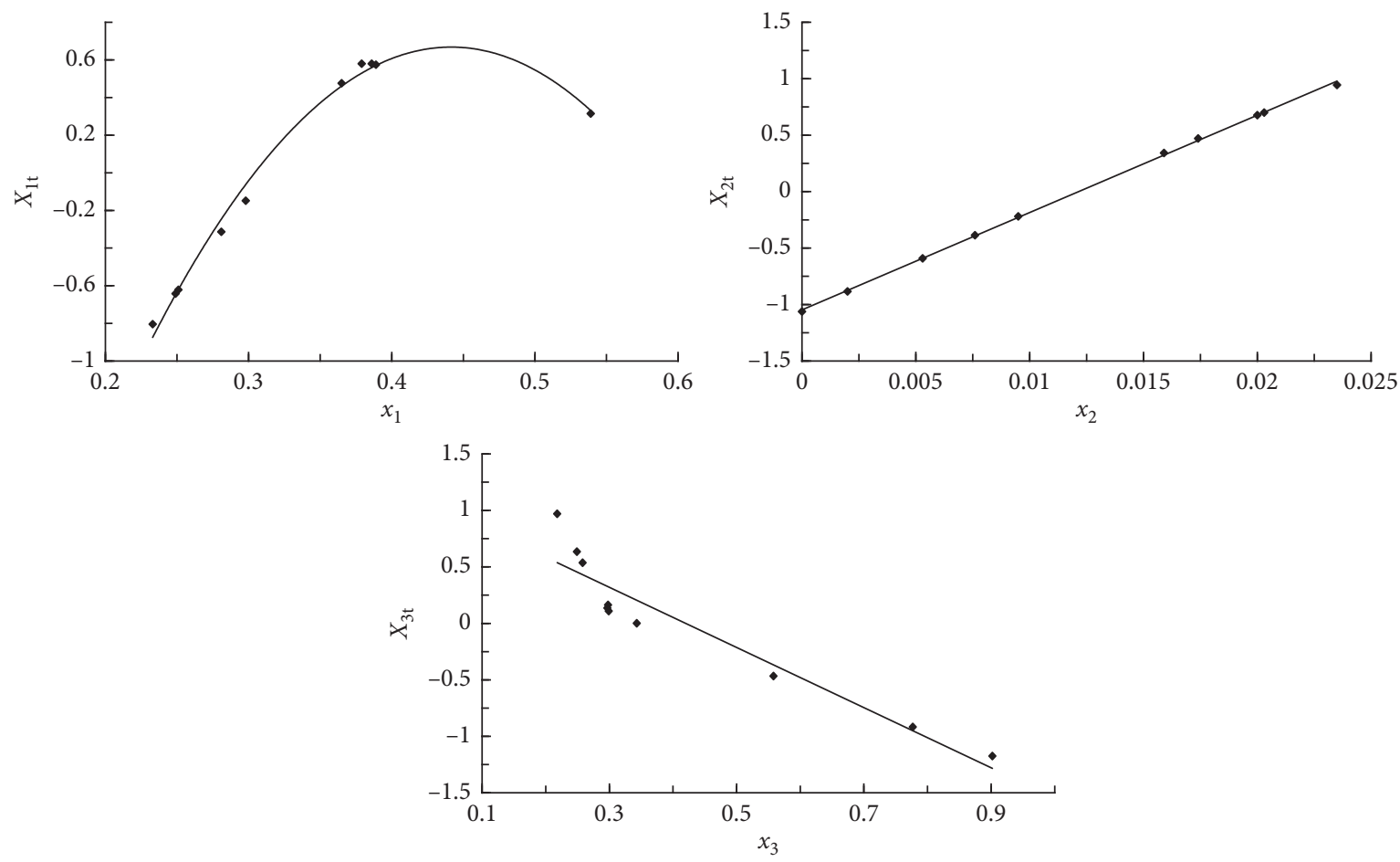

(b)

FIgURE 7: Transformation correlation: (a) mapping relationships for regression target $y_{1}$ (ultimate tensile strain $\varepsilon_{\mathrm{cu}}$ ); (b) mapping relationships for regression target $y_{2}$ (fracture energy $G_{\mathrm{F}}^{\mathrm{I}}$ ).

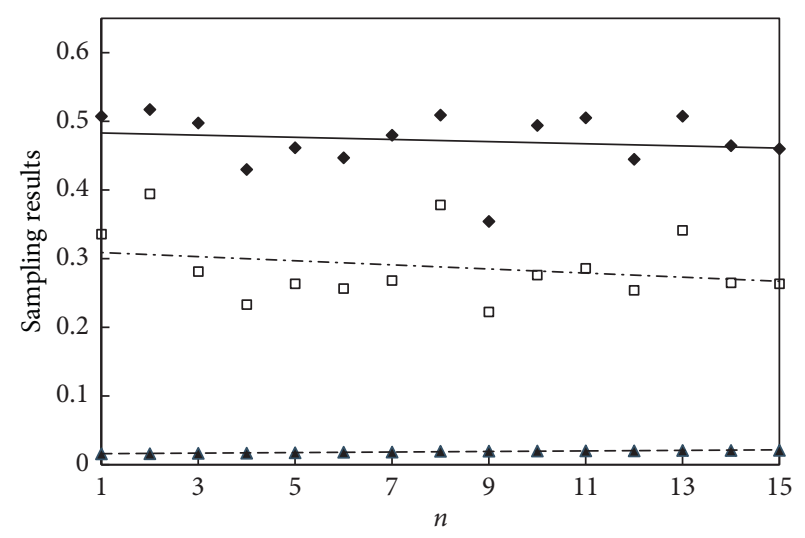

- $\mathrm{W} / \mathrm{B}$

$\square \mathrm{S} / \mathrm{B}$

$\Delta \mathrm{F} / \mathrm{B}$

FIGURE 8: Sampling results for regression target $y_{1}$ (ultimate tensile strain $\varepsilon_{\mathrm{cu}}$ ).

Figure 11. The crack width under load is less than $80 \mu \mathrm{m}$ and the number of crack width is nearly 20 in the tested section (50 $\mathrm{mm}$ zone), as shown in Figure 11.

4.2. Four-Point Bending Tests. The mix proportion $\mathrm{P}_{3}$ was used in the four-point bending tests, and the dimensions of three specimens were $400 \mathrm{~mm} \times 100 \mathrm{~mm} \times 15 \mathrm{~mm}$. The specimens were tested under displacement control

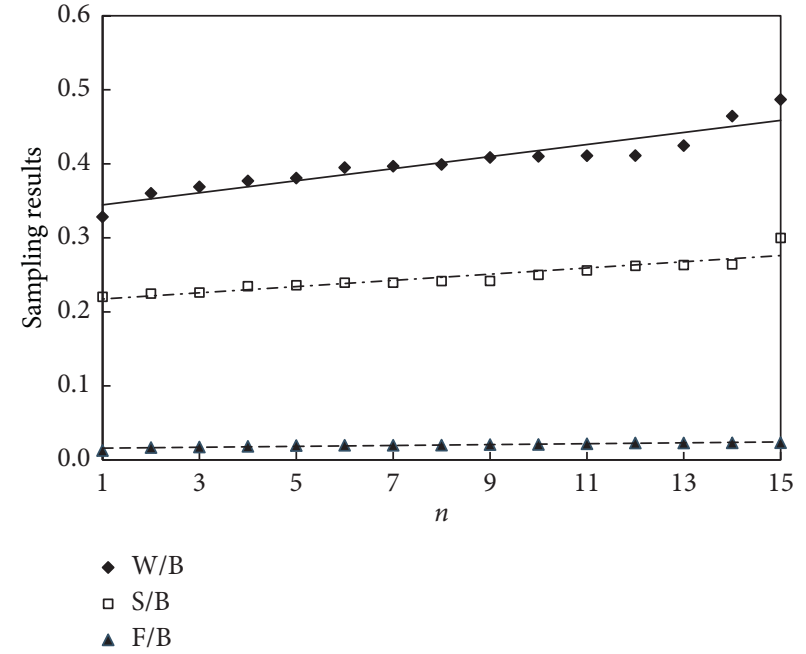

FIGURE 9: Sampling results for regression target $y_{2}$ (fracture energy $G_{\mathrm{F}}^{\mathrm{I}}$ ).

$(0.3 \mathrm{~mm} / \mathrm{min}$ loading rate $)$ in a $10 \mathrm{kN}$ capacity electromechanical universal testing machine, as shown in Figure 12. The reaction force and the loading point were recorded by the load cell there. The load-displacement curves are presented in Figure 13. Multiple cracking also occurred for the 3 specimens. The test results indicated that the bending specimen showed a good flexural toughness, energy absorption capacity, strain hardening, and crackcontrol capacity. 
TABLE 13: Range of ECC optimized mix proportions (mass ratio).

\begin{tabular}{lccc}
\hline Target & W/B & S/B & \\
\hline$\varepsilon_{\text {cu }}$ & $0.35 \sim 0.5$ & $0.25 \sim 0.3$ & 0.02 \\
$G_{\mathrm{F}}$ & $0.3 \sim 0.42$ & $0.2 \sim 0.3$ & 0.02 \\
$\varepsilon_{\mathrm{cu}}$ and $G_{\mathrm{F}}$ & $0.35 \sim 0.42$ & $0.25 \sim 0.3$ & 0.02 \\
\hline
\end{tabular}

TABLE 14: Randomly selected ECC mix proportions (mass ratio).

\begin{tabular}{lccccccccc}
\hline No. & Cement & Fly ash & w/c & Fiber & Quartz sand & Water-reducing admixture & W/B & S/B & F/B \\
\hline P1 & 1.0 & 1.20 & 0.770 & 0.044 & 0.60 & 0.003 & 0.012 & 0.35 & 0.27 \\
P2 & 1.0 & 0.35 & 0.530 & 0.030 & 0.40 & 0.001 & 0.39 & 0.30 & 0.02 \\
P3 & 1.0 & 1.50 & 1.050 & 0.050 & 0.64 & 0.011 & 0.42 & 0.26 & 0.02 \\
P4 & 1.0 & 2.30 & 1.200 & 0.063 & 0.90 & 0.009 & 0.36 & 0.27 & 0.02 \\
P5 & 1.0 & 0.8 & 0.667 & 0.033 & 0.50 & 0.37 & 0.28 & 0.02 \\
\hline
\end{tabular}

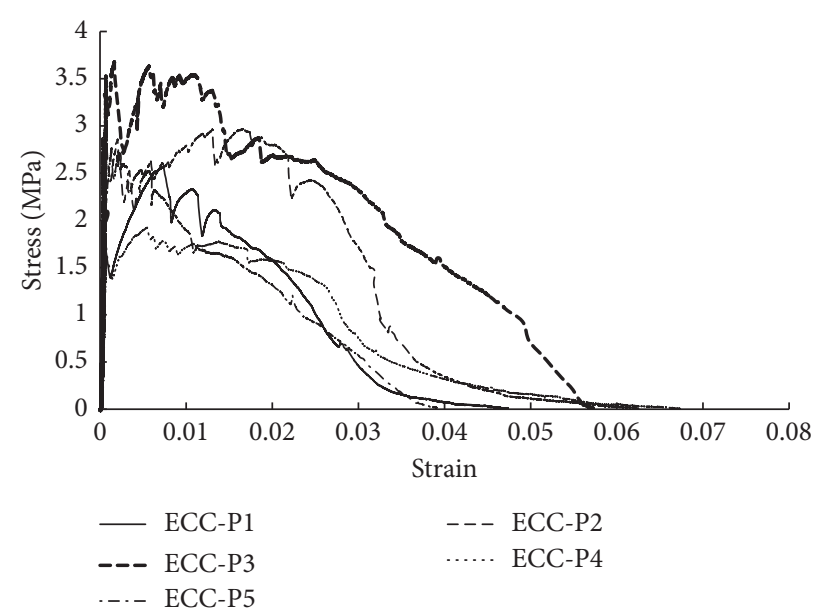

FIGURE 10: Uniaxial tensile stress-strain curves for the five selected optimized mix proportions.

TABLE 15: Verification test results for the selected ECC mix proportions.

\begin{tabular}{lccccc}
\hline Optimized target & $\mathrm{P}_{1}$ & $\mathrm{P}_{2}$ & $\mathrm{P}_{3}$ & $\mathrm{P}_{4}$ & \\
\hline$\varepsilon_{\text {cu }}(\%)$ & 4.7 & 6.7 & 5.6 & 6.7 & 3.8 \\
$G_{\mathrm{F}}^{\mathrm{I}}\left(\mathrm{N} \cdot \mathrm{m}^{-1}\right)$ & 2599.64 & 4335.61 & 5980.43 & 2732.23 & 2546.78 \\
\hline
\end{tabular}

4.3. Scanning Electron Microscope Tests. Scanning electron microscope was used to detect the distribution of PVA fibers in the cement matrix. The detection samples were randomly adopted from the specimens of $\mathrm{P}_{3}$ with the highest $G_{\mathrm{F}}^{\mathrm{I}}$ and $\mathrm{P}_{2}$ with the smallest fiber mass ratio (Table 14). The samples were about $5 \mathrm{~mm}$ in length, $3 \mathrm{~mm}$ in width, and $2 \mathrm{~mm}$ in thickness. The volume was about $30 \mathrm{~mm}^{3}$. The detected images within the scanning domain are presented in Figure 14, which shows that the fibers were uniformly distributed in the cement matrix.

The volume of the dumbbell-shaped specimen was about $245 \mathrm{~cm}^{3}$. According to the fiber/cement mass ratios of $\mathrm{P}_{3}$ and $\mathrm{P}_{2}$ in Table 14 and the $1.3 \mathrm{~g} / \mathrm{cm}^{3}$ fiber density, the fiber volume ratio can be obtained according to equation (9), and the total fiber volumes $V_{\text {total-f }}$ can be obtained, which are $4.05 \mathrm{~cm}^{3}$ and $4.63 \mathrm{~cm}^{3}$, respectively. According to the fiber diameter $(39 \mu \mathrm{m})$, length $(12 \mathrm{~mm})$, and density $\left(1.3 \mathrm{~g} / \mathrm{cm}^{3}\right)$, the volume of a single fiber $V_{\mathrm{f}}$ is about $0.0143 \mathrm{~mm}^{3}$. Therefore, the total number of fibers in the detected sample should be $V_{\text {total-f }} / V_{\mathrm{f}}$, which is about $2.8 \times 10^{5}$ and $3.2 \times 10^{5}$, respectively. If the fiber is uniformly distributed in the specimen, the theoretical fiber number within the $30 \mathrm{~mm}^{3}$ detected sample can be calculated, which should be 35 and 40 , respectively. The number of fibers was carefully counted using the scanning photos of the detected specimens. As the sample size was very small and most of the fibers penetrated the detected sample, one image of each specimen was enough for counting the fibers. However, the fibers were soft, which induced a curved shape in the matrix. Considering the irregular distribution of the soft fibers, the counted number of the fibers in the detected sample should be larger than the theoretical value. The counted number of fibers in $\mathrm{P}_{3}$ is 41 , 


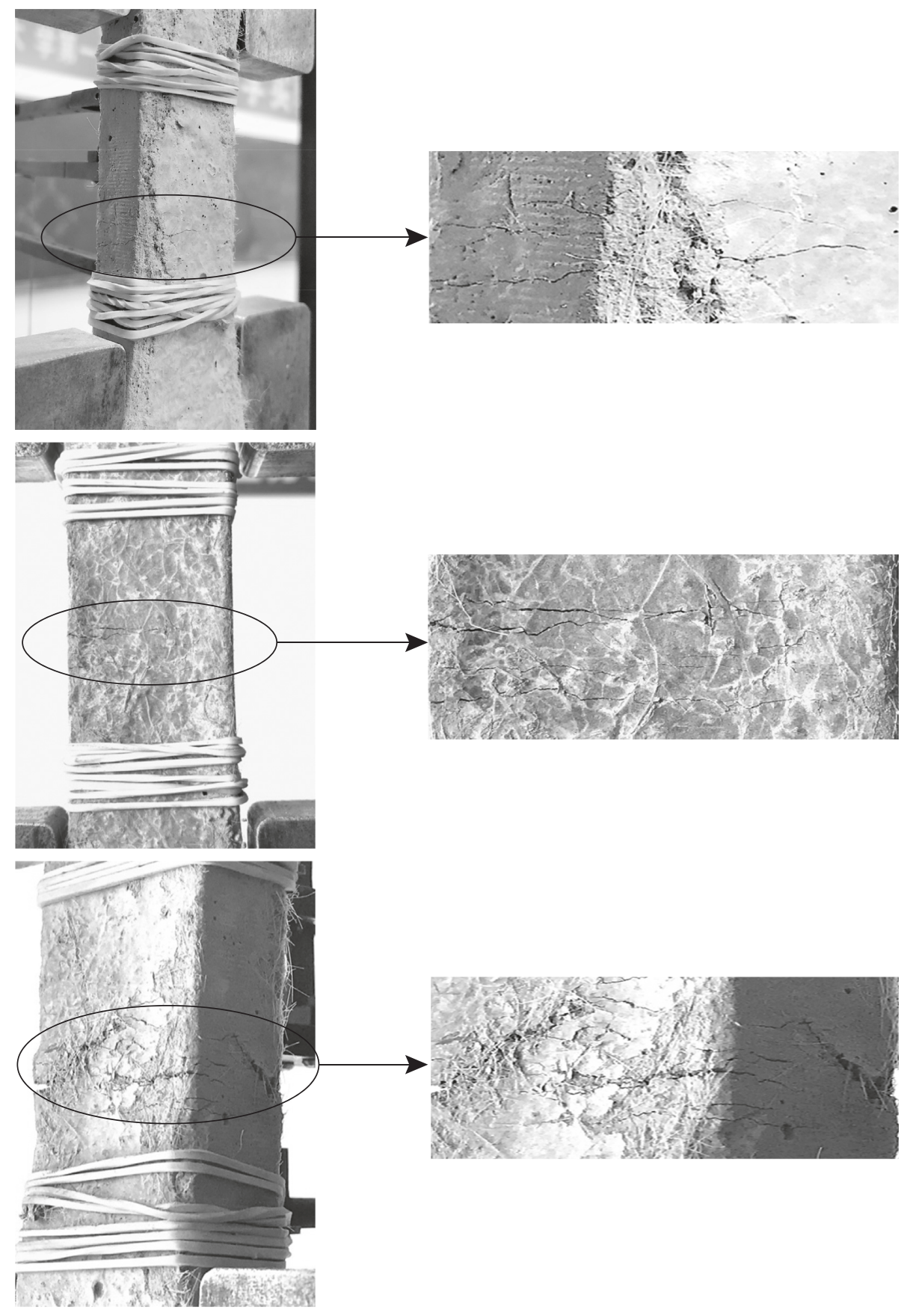

FIgUre 11: The failure modes of uniaxial tensile test for ECC- $\mathrm{P}_{3}$.

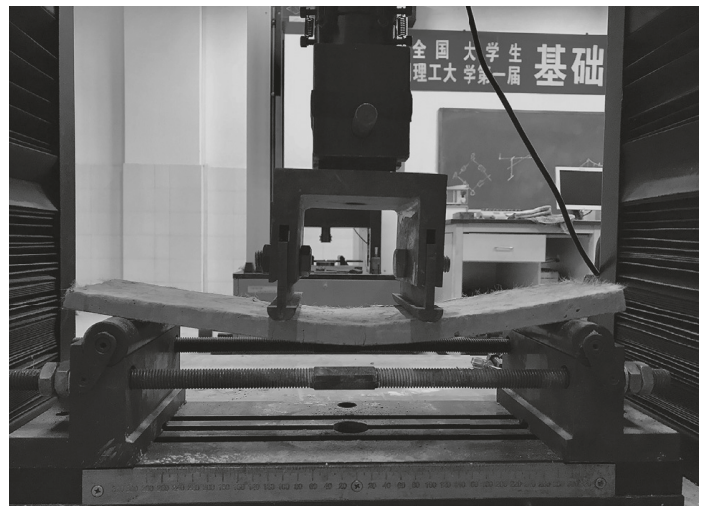

FIGURE 12: Four-point bending test arrangement for ECC- $\mathrm{P}_{3}$. 


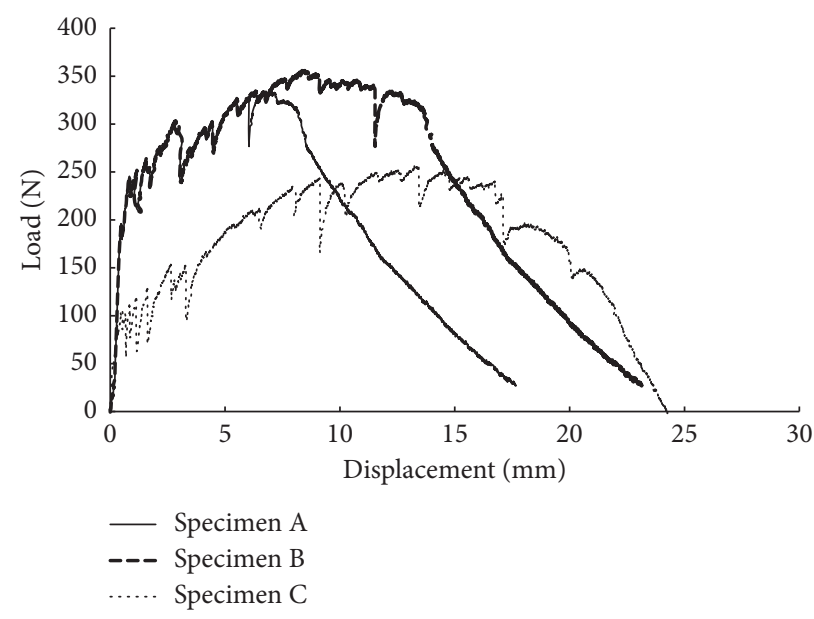

FIGURE 13: Four-point bending test load-displacement curves for ECC- $\mathrm{P}_{3}$.

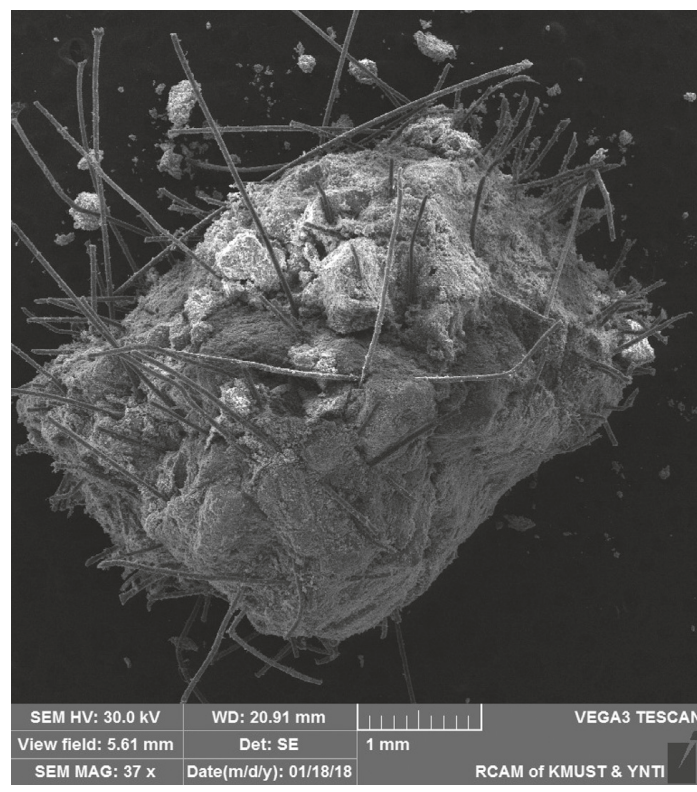

(a)

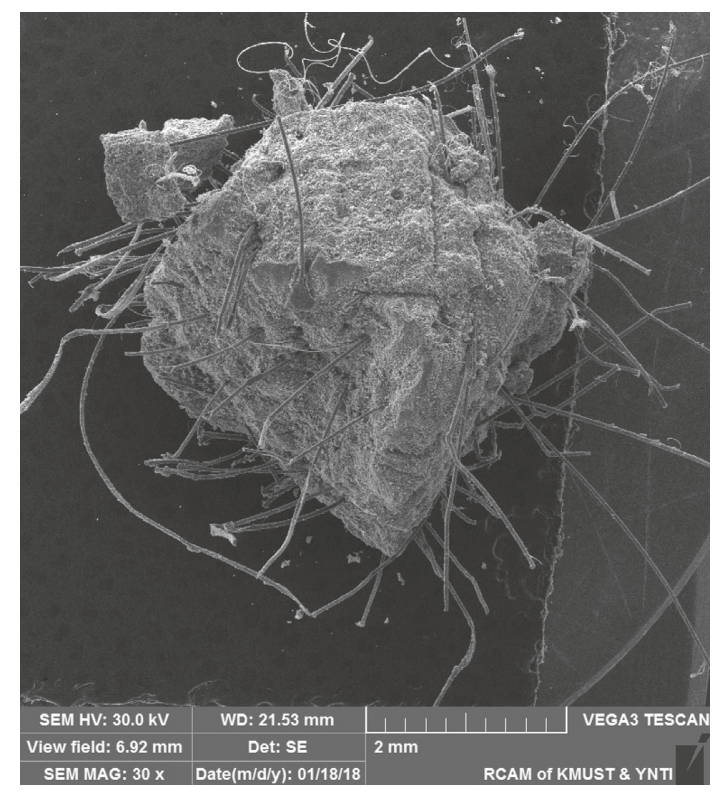

(b)

FIgURE 14: PVA fibers distribution in cement matrix: (a) ECC- $\mathrm{P}_{2}$; (b) ECC- $\mathrm{P}_{3}$.

where its theoretical value is 35 . The counted number of fibers in $\mathrm{P}_{2}$ is 48 , of which its theoretical value is 40 . The counted fiber numbers were greater than the theoretical values. The differences between the counted and theoretical fiber numbers in the detected samples did not exceed $20 \%$. The fibers were uniformly distributed in the ECC specimens, leading to a high ultimate tensile strain and high fracture energy capacity.

\section{Conclusions}

(1) The ECC mix proportion optimization design was successfully completed with the uniform design test method and alternating conditional expectation based on the local materials and industry wastes in
Kunming, Yunnan province, China. Only $10 \mathrm{mix}$ proportions were needed to be tested according to the uniform design. Based on the test data and the alternating conditional expectation, $\varepsilon_{\mathrm{cu}-\max }$ and $G_{\mathrm{F}-\max }$ were chosen as the optimization targets, and the $\mathrm{W} / \mathrm{B}$, $\mathrm{S} / \mathrm{B}$, and $\mathrm{F} / \mathrm{B}$ ranges, which were $0.35-0.42,0.25-0.3$, and 0.02 , respectively, were achieved.

(2) The validation tests were conducted, and the tested proportions were randomly adopted within the range of $\mathrm{W} / \mathrm{B}, \mathrm{S} / \mathrm{B}$, and $\mathrm{F} / \mathrm{B}$. The ultimate tensile strain $\varepsilon_{\mathrm{cu}}$ and fracture energy $G_{\mathrm{F}}^{\mathrm{I}}$ were tested. Results showed that the ECC ultimate tensile strain $\varepsilon_{\mathrm{cu}}$ was between $3.8 \%$ and $6.7 \%$, which was $300-500$ times that of normal concrete. The ECC fracture energy $G_{\mathrm{F}}^{\mathrm{I}}$ was between $2546.78 \mathrm{~N} / \mathrm{m}$ and $5980.43 \mathrm{~N} / \mathrm{m}$, which 
was 10-20 times that of normal concrete. All of the specimens possessed large ultimate tensile strain and energy absorption capacity.

(3) In the four-point bending test, the ECC specimens showed remarkable ductility, flexural toughness, and energy absorption capacity. Strain hardening and crack-control capacity were also observed. Multiple cracking occurred during the specimen failure process.

(4) The PVA fiber distribution in the cement matrix was detected using SEM, and results showed that the fibers were uniformly distributed in the cement matrix. Thus, the ECC mixing process used in the tests has good feasibility.

\section{Data Availability}

The data used to support the findings of this study are available from the corresponding author upon request.

\section{Conflicts of Interest}

The authors declare that there are no conflicts of interest regarding the publication of this paper.

\section{Acknowledgments}

This work was supported by the National Natural Science Foundation of China (Grant nos. 51968035, 51308271, and 51768028) and Yunnan Province Educational Commission of Scientific Research Foundation of China (Grant no. 2019J0043).

\section{References}

[1] S. M. Abbasi, H. Ahmadi, G. Khalaj, and B. Ghasemi, "Microstructure and mechanical properties of a metakaolinitebased geopolymer nanocomposite reinforced with carbon nanotubes," Ceramics International, vol. 42, no. 14, pp. 15171-15176, 2016.

[2] A. Nazari and G. Khalaj, "Prediction compressive strength of lightweight geopolymers by ANFIS," Ceramics International, vol. 38, no. 6, pp. 4501-4510, 2012.

[3] G. Khalaj, S. E. S. Hassani, A. Khezrloo, and E.-A.-D. Haratifar, "Split tensile strength of OPC-based geopolymers: application of DOE method in evaluating the effect of production parameters and their optimum condition," Ceramics International, vol. 40, no. 7, pp. 10945-10952, 2014.

[4] V. C. Li, "Tailoring ECC for special attributes: a review," International Journal of Concrete Structures and Materials, vol. 6, no. 3, pp. 135-144, 2012.

[5] X. Li, Y. Bao, L. Wu et al., "Thermal and mechanical properties of high-performance fiber-reinforced cementitious composites after exposure to high temperatures," Construction and Building Materials, vol. 157, pp. 829-838, 2017.

[6] V. C. Li, "Advances in ECC research," Special Publication of ACI, vol. 206, pp. 373-400, 2002.

[7] Y. Li, Z. J. Liu, and X. W. Liang, "Uniaxial tensile properties of high performance PVA fiber cement composites," Chinese Journal of Mechanical Engineering, vol. 30, pp. 322-330, 2013.
[8] F. G. Jia and G. S. Song, Civil Engineering Material, Tsinghua University Press, Beijing, China, 2016.

[9] W. Zuo, J. E, X. Liu, Q. Peng, Y. Deng, and H. Zhu, "Orthogonal experimental design and fuzzy grey relational analysis for emitter efficiency of the micro-cylindrical combustor with a step," Applied Thermal Engineering, vol. 103, pp. 945-951, 2016.

[10] JGJ 55-2011, Specification for Mix Proportion Design of Ordinary Concrete, Standardization Administration of China, Beijing, China, 2011.

[11] K. T. Fang and C. X. Ma, Orthogonal and Uniform Experimental Design, Science Press, Beijing, China, 2001.

[12] G. Khalaj and A. Nazari, "Modeling split tensile strength of high strength self compacting concrete incorporating randomly oriented steel fibers and $\mathrm{SiO}_{2}$ nanoparticles," Composites Part B: Engineering, vol. 43, no. 4, pp. 1887-1892, 2012.

[13] M. K. Deng, H. Z. Sun, X. W. Liang, and W. B. Jing, "Experimental study on compressive behavior and flexural behavior of ductile fiber reinforced concrete," Industrial Construction, vol. 44, pp. 107-112, 2014.

[14] K. T. Fang and Y. Wang, Number-Theoretic Methods in Statistics, Science Press, Beijing, China, 1996.

[15] K. T. Fang, Uniform Design and Uniform Design Table, Science Press, Beijing, China, 1994.

[16] L. Breiman and J. H. Friedman, "Estimating optimal transformations for multiple regression and correlation," Journal of the American Statistical Association, vol. 80, no. 391, pp. 580-598, 1985.

[17] S. J. Yang and Y. H. Li, "Comparative analysis and application of parametric regression and nonparametric regression in FDI," Statistics and Decision, vol. 6, pp. 31-34, 2017.

[18] S. Y. Zhang, X. Q. Ge, and B. Wang, "Nonparametric regression with applications," The Journal of Quantitative Economics, vol. 10, pp. 60-65, 1997.

[19] X. Y. Huang, Statistics, Chongqing University Press, Chongqing, China, 2015.

[20] K. T. Fang, Applied Regression Analysis, Science Press, Beijing, China, 1988.

[21] Insightful Corporation, S-PLUS 8 Guide to Statistics, MathSoft, Inc., Seattle, WA, USA, 2007.

[22] S. Y. Li, Y. Q. Chen, and Y. Li, Ant Colony Algorithms with Applications, Harbin Institute of Technology Press, Harbin, China, 2004.

[23] D. Meng, T. Huang, Y. X. Zhang, and C. K. Lee, "Mechanical behaviour of a polyvinyl alcohol fibre reinforced engineered cementitious composite (PVA-ECC) using local ingredients," Construction and Building Materials, vol. 141, pp. 259-270, 2017.

[24] Z. Pan, C. Wu, J. Liu, W. Wang, and J. Liu, "Study on mechanical properties of cost-effective polyvinyl alcohol engineered cementitious composites (PVA-ECC)," Construction and Building Materials, vol. 78, pp. 397-404, 2015.

[25] K. Tosun-Felekoglu, B. Fekejoglu, R. Ranade, B. Y. Lee, and V. C. Li, "The role of flaw size and fiber distribution on tensile ductility of PVA-ECC," Composites Part B: Engineering, vol. 56, pp. 536-545, 2014.

[26] S. Wang and V. C. Li, "Polyvinyl alcohol fiber reinforced engineered cementitious composites: material design and performances," in Proceedings of the International RILEM Workshop on HPFRCC in Structural Applications, pp. 65-73, Honolulu, HI, USA, May 2005.

[27] T. Kanda and V. C. Li, "Practical design criteria for saturated pseudo strain hardening behavior in ECC," Journal of Advanced Concrete Technology, vol. 4, no. 1, pp. 59-72, 2006. 
[28] V. C. Li, C. Wu, S. X. Wang, A. Ogawa, and T. Saito, "Interface tailoring for strain-hardening polyvinyl alcohol-engineered cementitious composite (PVA-ECC)," ACI Materials Journal, vol. 99, no. 5, pp. 463-472, 2002.

[29] M. D. Lepech and V. C. Li, "Application of ECC for bridge deck link slabs," Materials and Structures, vol. 42, no. 9, pp. 1185-1195, 2012.

[30] J. H. Yu and V. C. Li, "Research on production, performance and fibre dispersion of PVA engineering cementitious composites," Materials Science and Technology, vol. 25, no. 5, pp. 651-656, 2009.

[31] S. L. Gao and S. L. Xu, "Experimental research on tension property of polyvinyl alcohol fiber reinforced cementitious composites," Journal of Dalian University of Technology, vol. 47, pp. 233-239, 2007.

[32] C. X. Gong and J. Zhang, "Tensile performance of high ductile fiber reinforced cementitious composite," Journal of $\mathrm{Hy}$ draulic Engineering, vol. 39, pp. 361-366, 2008.

[33] W. Wang, Z. F. Pan, S. P. Meng, and Z. Qiao, "Study on mechanical properties of domestic PVA fiber reinforced cementitious composite," China Industrial Construction, vol. 1, pp. 958-964, 2014

[34] Z. Yang, Experimental Analysis on Shear Performance of Ultra-high Toughness Cementitious Composites Members, Ph.D. thesis, Hefei University of Technology, Hefei, China, 2014

[35] H. Q. Xue and Z. C. Deng, "Experimental study of engineering cementitious composites," Chinese Journal of Southeast University, vol. 40, pp. 20-27, 2010.

[36] JGJ 98-2010, Specification for Mix Proportion Design of Masonry Mortar, Standardization Administration of China, Beijing, China, 2010.

[37] M. Xu, Y. Bao, K. Wu, H. Shi, X. Guo, and V. C. Li, "Multiscale investigation of tensile properties of $\mathrm{TiO}_{2}$-doped engineered cementitious composite," Construction and Building Materials, vol. 209, pp. 485-491, 2019.

[38] Y. Bao, M. Xu, D. Soltan et al., "Three-dimensional printing multifunctional engineered cementitious composites (ECC) for structural elements," in RILEM Bookseries, pp. 115-128, Springer, Berlin, Germany, 2018. 


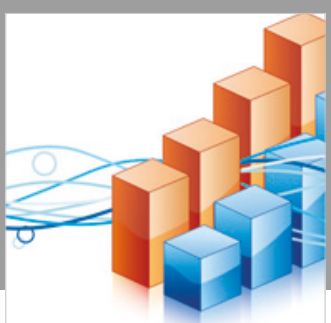

Advances in

Operations Research

\section{-n-m}
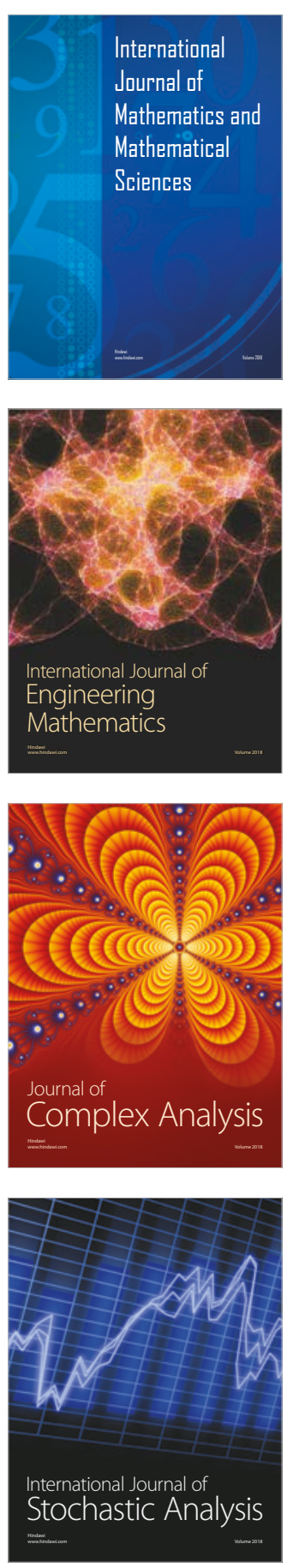
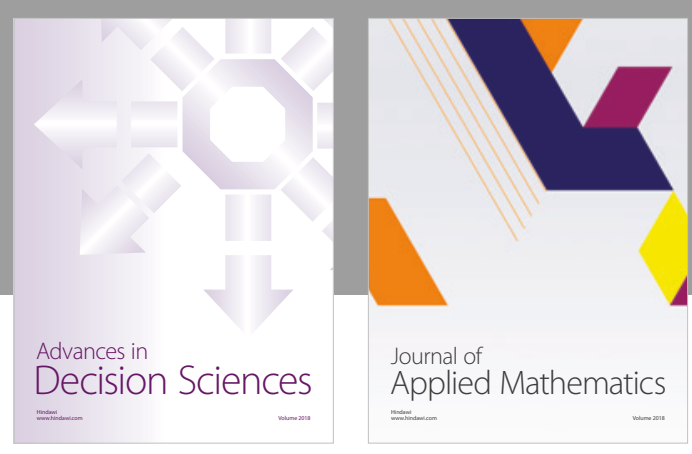

Journal of

Applied Mathematics
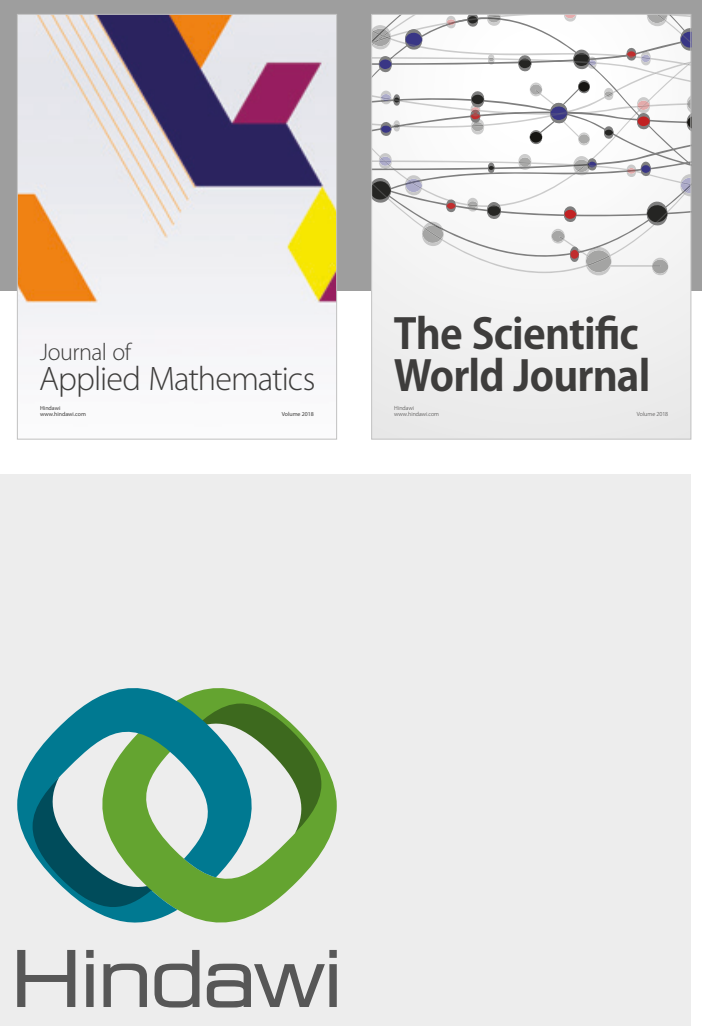

Submit your manuscripts at

www.hindawi.com

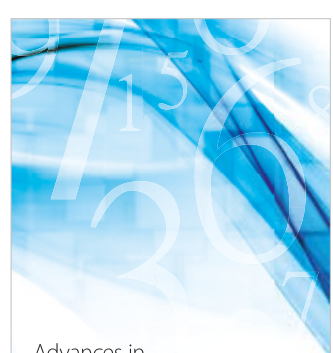

Advances in
Numerical Analysis
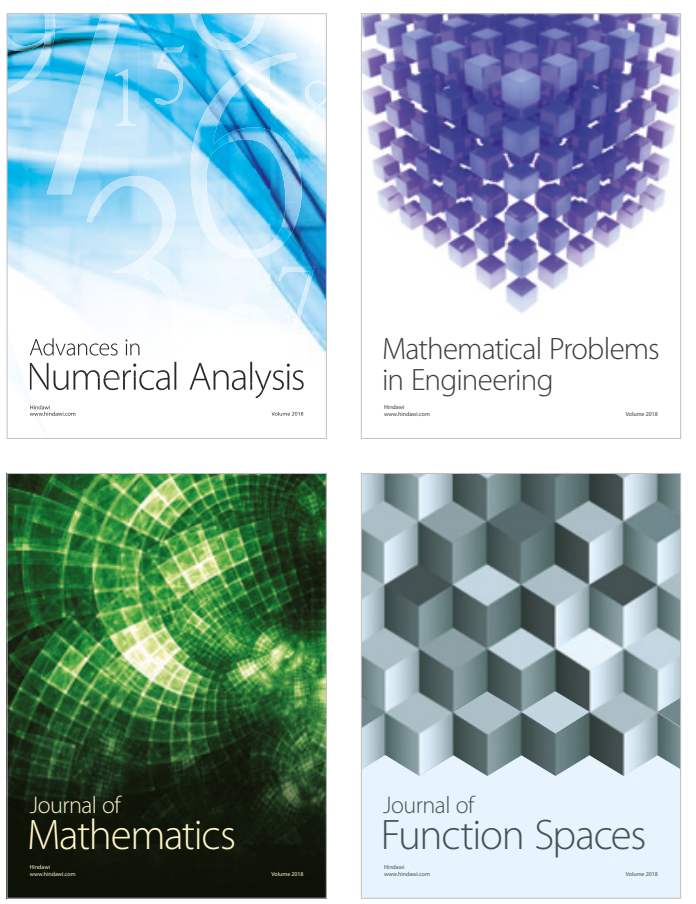

Mathematical Problems in Engineering

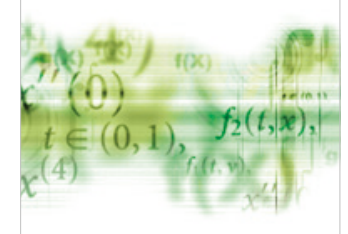

International Journal of

Differential Equations

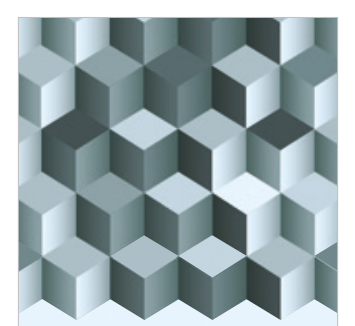

Journal of

Function Spaces

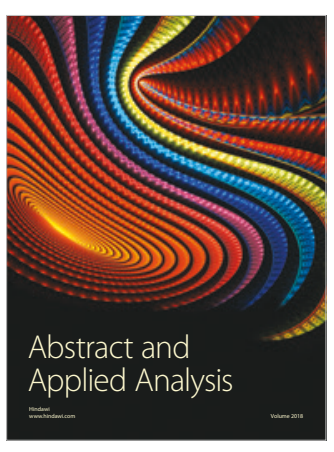

The Scientific

World Journal

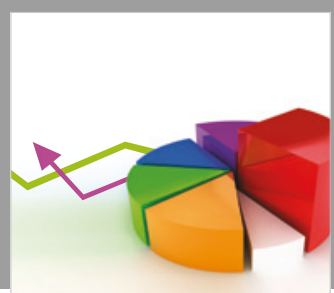

Journal of

Probability and Statistics
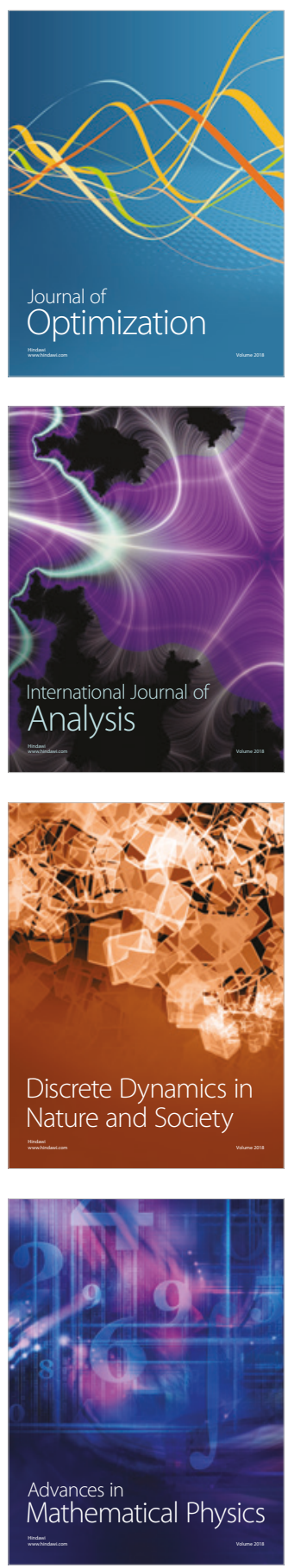